\title{
Engaging Students via Student-Unique Weekly Assessed Tutorial Sheets: A Four Year Review
}

\author{
Mark Russell \\ University of Hertfordshire, United Kingdom, m.b.russell@herts.ac.uk
}

\begin{abstract}
Following unacceptable examination performance in a core engineering module, (Fluid Mechanics and Thermodynamics), an alternative and innovative approach to assessment was developed. The new approach centered on the use of student unique Weekly Assessed Tutorial Sheets (WATS). The emphasis on assessment arises because of i) the overwhelming evidence that assessment plays a significant part in student learning - good assessment guides the students' effort towards the intended learning outcomes and helps distribute their effort across both the curriculum topics and the semester, and ii) the previous assessment programme did little to promote learning nor support teaching.

This paper outlines the new development and presents findings from its use across four years. Since its implementation all performance indicators have improved. Students are now more actively engaged with the module, teachers are now provided with information on the students' current (mis)-conceptions and examination scores have improved. Feedback from the students on the various features of the assessment programme is encouraging as is their feedback relating their perception of the assessment programme to scaffold their learning. Many students, however, still note the importance of grades, however, in driving their effort.

Index Terms - assessment, feedback, technology.
\end{abstract}

\section{INTRODUCTION}

High module failure rates demand attention. In some instances a student may fail a module (course) due to its complexity whereas in other instances a student may fail due to their inappropriate study behaviors and/or their disengagement with the learning resources.

The study behaviors of a student and their approach to learning are typically not personality traits but rather are motivated by the prevailing learning environment. Descriptions of alternative approaches to learning and suggestions of those features of a learning environment that might orientate a student to adopt a deep (meaning making) approach to their learning versus those features that might inadvertently encourage a surface (reproducing) approach to learning can be found in the literature [1].

Low examination scores in a core first year engineering module in 2000/01 (Fluid Mechanics and Thermodynamics), forced a revisit to principles considered good practice in undergraduate education as well as the features of a learning environment that might encourage a deep approach to learning.

Analysis of the students' performance, their study behaviors and their approach to learning identified the less than optimal stimulus provided by the assessment. In this module the assessment comprised two laboratory studies, an in-module phase test and a final end of module examination. The laboratory studies were included to engage the students in experiential learning and to provide an opportunity for them to see how their classroom studies translate to real world examples, the theory/practice nexus. The final examination was included to satisfy the requirements to establish the students' individual understanding of the module. The phase test, which was set around week eight of twelve, was intended to stimulate revision and engage the students with the learning resources covered to date. The analysis of failure suggested that issuing the assessment at week eight provided limited encouragement for the students to explore the subject much before week seven. Further, due to its timing and the increasing demands placed on teaching staff, the feedback arising from the phase test was provided too late for it to be effective. In this instance there was a misalignment between the expected student study patterns and the prevailing learning environment. Trying to establish regular engagement via one-off assessments set towards the end of the module was a little ambitious. This point is captured by one commentator when he writes 'the methods we use to assess students are one of the most critical of all influences on their learning' [2]

The significance of assessment on student engagement and learning is a repeated feature of the literature. A study of some UK diary studies notes how the diary entries, 'confirmed the extent to which students devote their out-ofclass study time almost exclusively to assessed tasks. Take away the assessment and you lose the effort and the learning' [3]. Further, when offering the benefits of aligned teaching, Biggs [1] notes 'assessment is the senior partner in learning and teaching; Get it wrong and the rest collapses'. This point is particularly important since 'students can with difficulty escape from the effects of poor teaching they cannot (by definition if they wish to graduate) escape the effects of poor assessment' [4]. Whilst assessment is important for learning, its impact on behaviors is also noted in the literature, 'if you want to change student learning then change the methods of assessment' [5].

October $22-25,2008$, Saratoga Springs, NY $38^{\text {th }}$ ASEE/IEEE Frontiers in Education Conference 
Session S2B

In response to the identified issues and the noted backwash of assessment impacting on the students' learning and their study behaviors there was a need to modify the assessment. The failing of the students was brought about by a failing assessment programme. The following section introduces the themes underpinning the development of a new assessment programme and outlines some of its features.

\section{THE DEVELOPMENT - UNDERPINNING PEDAGOGY}

Drawing on the literature, for example the seven principles of good practice [6], suggestions on how people learn [7], guidance on effective assessment and feedback [8\&9] and the necessity to balance the effectiveness of the assessment with its efficiency [10], led to the development of three underpinning themes. These themes, supported by a set of principles, provided the pedagogic framework on which to the new assessment programme was based.

Theme 1. Alignment; the assessment programme shall...

- connect the assessment tasks to the module learning outcomes

- compliment and support the existing appropriate teaching and learning settings

- inform teachers of their students' progress

Theme 2: Learning focused; the programme shall...

- focus the students' effort on learning

- $\quad$ respect and support the individual student whilst also valuing the learning benefits to be realized from mutual peer-to-peer support

- be feedback-rich

Theme 3. Resourceful; the assessment programme shall...

- not be overly demanding on the available resources

\section{THE DEVELOPMENT - WEEKLY ASSESSED TUTORIAL SHEETS (WATS)}

From the underpinning themes the Weekly Assessed Tutorial Sheets (WATS) assessment programme was created to, inter alia,

- Motivate weekly participation and consolidation of the lecture via practice opportunity

- $\quad$ Provide the students with prompt feedback

- Facilitate student-to-student cooperation whilst restricting the benefit of answer sharing

- Provide evidence to teachers regarding the students progress and

- Generate information on which teachers could make informed teaching adaptations

Example products of the assessment programme follow. An example of a part WATS is shown in Figure 1, the student unique data is highlighted.

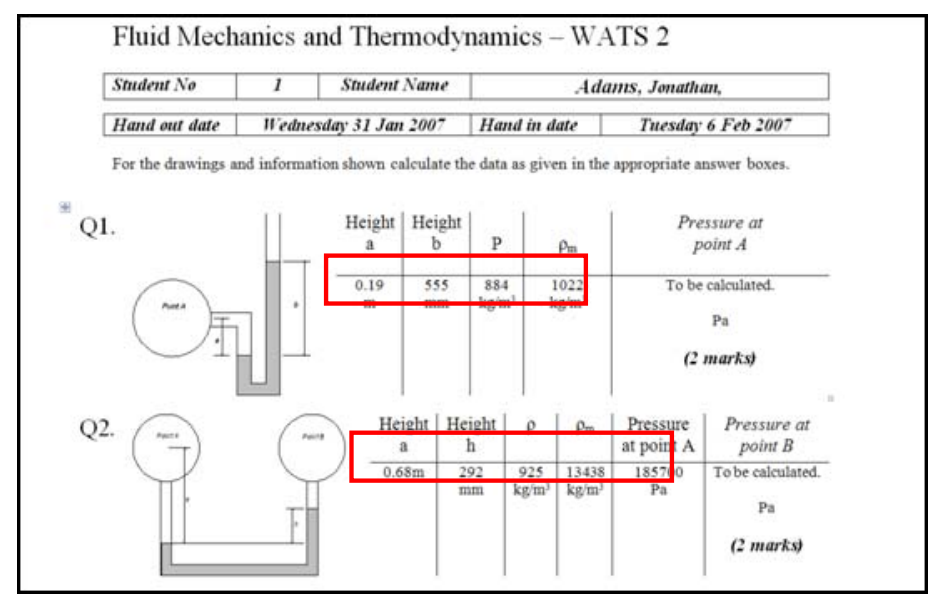

FIGURE 1

PART OF A WeEkly ASSESSEd Tutorial Sheet (WATS)

Following completion of the task the students are required to submit their responses to a dedicated WATS Data Gatherer see Figure 2. The WATS Data Gatherer is a web based application and allows anyplace - anytime access.

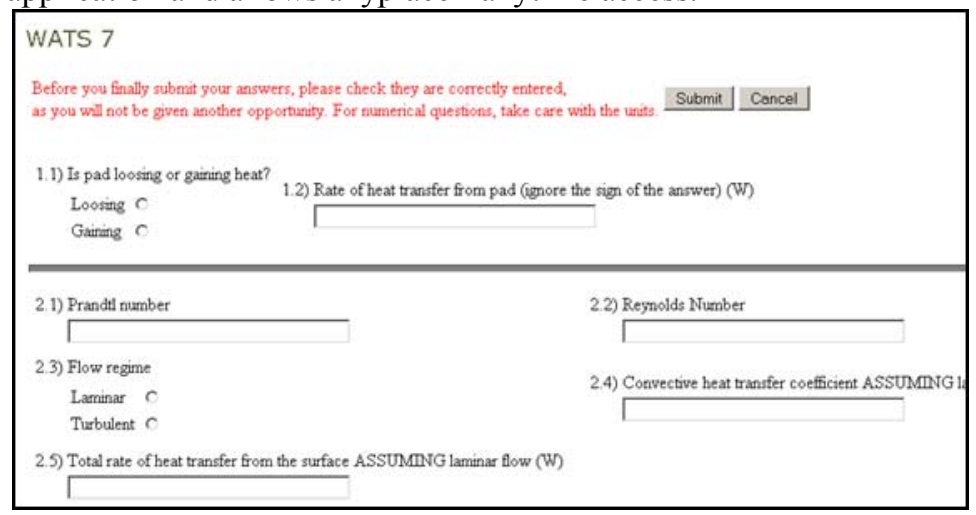

FIGURE 2

THE WATS DATA GATHERER

After the submission deadline has past Microsoft Excel ${ }^{\mathrm{TM}}$ is used to read the students submissions, submitted to the WATS Data Gatherer, mark the work and provide individual feedback e-mails. These tasks are automated and made possible by the inclusion of Visual Basic for Applications (VBA) routines. The VBA enhanced spreadsheet is referred to as the WATS Marking Wizard.

Additionally the WATS Marking Wizard provides information to teachers. This is useful for teachers wanting to make informed teaching adaptations based on the students' demonstrable understanding of the weekly topic areas. For further discussion see [11].

\section{ReSUlTS}

During the period 2000/01-2005/06 the majority of the teaching and learning settings remained constant. The major difference during this period was the introduction of the WATS approach to assessment in 2001/02. This was used in all subsequent years and replaced the previously described

October 22 - 25, 2008, Saratoga Springs, NY 
Session S2B

in-module phase test. Sample results collected during this period are presented and include the impact of the assessment programme on student study behaviors and the students' performance. Additionally the students' view of the assessment is presented.

\section{Impact on student study behaviors}

The number of students submitting a response to the weekly task is shown in Table I. The bracketed figure represents the percentage of students responding.

TABLE I.

COHORT SUBMISSION PROFILE

\begin{tabular}{|c|c|c|c|c|c|}
\hline & $2002-03$ & $2003-04$ & $2004-05$ & $2005-06$ & All years \\
\hline WATS 1 & $122(95 \%)$ & $133(100 \%)$ & $156(96 \%)$ & $173(101 \%)$ & $584(98 \%)$ \\
\hline WATS 2 & $123(96 \%)$ & $134(101 \%)$ & $159(98 \%)$ & $165(96 \%)$ & $581(97 \%)$ \\
\hline WATS 3 & $119(93 \%)$ & $132(99 \%)$ & $158(97 \%)$ & $171(99 \%)$ & $580(97 \%)$ \\
\hline WATS 4 & $114(89 \%)$ & $127(95 \%)$ & $158(97 \%)$ & $165(96 \%)$ & $564(95 \%)$ \\
\hline WATS 5 & $116(91 \%)$ & $135(102 \%)$ & $159(98 \%)$ & $170(99 \%)$ & $580(97 \%)$ \\
\hline WATS 6 & $116(91 \%)$ & $132(99 \%)$ & $150(92 \%)$ & $160(93 \%)$ & $558(94 \%)$ \\
\hline WATS 7 & $122(95 \%)$ & $128(96 \%)$ & $143(88 \%)$ & $159(92 \%)$ & $552(93 \%)$ \\
\hline WATS 8 & $116(91 \%)$ & $129(97 \%)$ & $142(87 \%)$ & $149(87 \%)$ & $536(90 \%)$ \\
\hline WATS 9 & $83(65 \%)$ & $114(86 \%)$ & $139(85 \%)$ & $157(91 \%)$ & $493(83 \%)$ \\
\hline WATS 10 & $96(75 \%)$ & $119(89 \%)$ & $131(80 \%)$ & $154(90 \%)$ & $500(84 \%)$ \\
\hline WATS 11 & $94(73 \%)$ & $112(84 \%)$ & $136(83 \%)$ & $150(87 \%)$ & $492(83 \%)$ \\
\hline Sum WATS & 1221 & 1395 & 1631 & 1773 & 6020 \\
\hline Average & $111(87 \%)$ & $127(95 \%)$ & $148(91 \%)$ & $161(94 \%)$ & $547(92 \%)$ \\
\hline nexam & 128 & 133 & 163 & 172 & 596 \\
\hline
\end{tabular}

The cohort submission profile shows that high proportions of the cohort were actively engaging with the subject each week. Across the four cohorts $92 \%$ of the students were engaged on the assessment tasks throughout the semester. Further, the students' active engagement was i) focused on tasks that were aligned with the learning outcomes and ii) distributed across both the subject domain and the semester. Both of which are congruent with the principles underpinning the development.

The total number of submissions and the number of submissions made a day or more before the submission deadline are presented in Table II. The data is constrained to the years 2003/04, 2004/05 \& 2005/06 because only these cohorts submitted their results through the WATS Data Gatherer. Submitting through the Data Gatherer ensures that the date and time are automatically added to the submissions.

TABLE II.

NUMBER OF SUBMISSIONS MADE A DAY BEFORE THE DEADLINE.

\begin{tabular}{c|c|c|c|c}
\multicolumn{6}{c}{ NUMBER OF SUBMISSIONS MADE A DAY BEFORE THE DEADLINE. } \\
& $2003-04$ & $2004-05$ & $2005-06$ & all years \\
\hline Day in advance & $108(7.7 \%)$ & $193(11.8 \%)$ & $236(13.3 \%)$ & $537(11.2 \%)$ \\
Total submissions & 1395 & 1631 & 1773 & 4799
\end{tabular}

Table II shows that only around $10 \%$ of the total number of submissions were made a full day before the submission deadline. This figure is similar across the three years. Whilst the majority of the students' submissions were made on the last day of the study period, which might indicate cramming, there is evidence on each year of the associated discussion forum that some students were thinking about, and working on, the tasks in the days preceding their submission. For

978-1-4244-1970-8/08/\$25.00 @2008 IEEE $38^{\text {th }}$ ASEE/IEEE Frontiers in Education Conference instance, the following was posted to the discussion forum on the 18th February 2004 and yet the student chose not to submit his results until the 24th February 2004; the last day of that week's study period. 'To Mark Russell, The last WATS 3 question is unclear what is meant by the horizontal floor of the tank, how is it different to the original position of the door'. (S58, 2003-04). Further, the following was posted on the 14th April 2005 whereas the student chose to submit on the 26th April 2005. 'I was attempting Wats 9 and $i$ got stuck on the first question because I found there was 2 unknowns when equating equations for both size disk in different fluids. The only assumption $i$ could come to was there should be an angular velocity given in the question for the first disc in the equation so that we can find the Dynamic Viscosity for the fluid for second disc. Hope this is clear.' (SXX, 2004-05). The first example demonstrates thinking about the task whereas the second demonstrates, by the student's own admission, working on the task. Both comments were posted to the discussion forum in the days preceding the submission deadline and the student's actual date of submission.

Whilst there is some evidence to suggest some of the students were working on the weekly tasks days before submitting, it is instructive also to look at the time of the students' submissions. Since this assessment exploits technology to collect the students' submissions the submission deadline is purposely not constrained to fall within normal working hours i.e. 9.00-17.00. Indeed the submission deadline for the assessment programme is set at midnight on the submission day. Table III summarizes the submission time profiles.

\begin{tabular}{r|cccc}
\multicolumn{5}{c}{ TABLE III } \\
SUBMISSION TIMES OF THE WATS & \\
& $2003 / 04$ & $2004 / 05$ & $2005 / 06$ & All years \\
\hline $9-5$ inc & $699(50.1 \%)$ & $745(44.5 \%)$ & $851(48 \%)$ & $2295(47.8 \%)$ \\
ouside $9-5$ & $696(49.9 \%)$ & $886(55.5 \%)$ & $922(52 \%)$ & $2504(52.2 \%)$ \\
Within last two hours & $244(17.5 \%)$ & $273(16.3 \%)$ & $244(13.8 \%)$ & $761(15.9 \%)$ \\
Within last hour & $135(9.7 \%)$ & $172(10.3 \%)$ & $137(7.7 \%)$ & $444(9.3 \%)$ \\
Total submissions & $1395(100 \%)$ & $1631(100 \%)$ & $1773(100 \%)$ & $4799(100 \%)$
\end{tabular}

Around half the students chose to submit their responses outside normal office hours, which is the time period when more conventional assessments are likely to be collected. The results also show that in all three cohorts around $15 \%$ of the submissions were made within the last two hours of the study period; two hours before the midnight submission deadline. Furthermore, $10 \%$ of the submissions were made within the last hour of the study period. To consolidate the lecture and provide appropriate practice opportunity the weekly tasks are created such that they demand around 1-2 hours of student effort. Hence if a submission is made 1 hour before the midnight submission deadline the likelihood is that the student is working on the task at that time too. Whilst this is not ideal the overwhelming evidence implies that most of the students were regularly engaged with learning activities and many were working on the tasks at an appropriate time. Many students commented on how the assessment programme impacted positively on their learning behaviors, for example one student writes 'I think wats was a good thing as it has made us all review our notes and

October 22 - 25, 2008, Saratoga Springs, NY S2B-9 
Session S2B

revise throughout the semester instead of throwing on the floor and not looking at them until the exam' (S78, 2003-04).

Other student comments are positive about the experience but note how they were forced to learn. This is probably due to the weekly tasks being graded and counting towards the final grade in the module. One student notes ' $I$ think it is a good approach to learning because it enables or rather "forces" us to work on the module every week, and this kind of helps sometimes' (S100, 2003-04). This point, including the notion of forcing, is also repeated by another student when he writes, It actually makes you do the work, or basically we are forced to do it also makes us learn what were doing' (S62, 2005-06).

The impact of the assessment programme on the student study behaviors is important. Creating a learning environment that stimulates activity is likely to lead to learning. A measure of this learning is given by reviewing the students' performance on the weekly tasks and the final module examination. The following section commences with the students' performance on the WATS tasks and then progresses to describe the students' examination performance. Relationships between the WATS and examination scores conclude the section.

\section{Impact on student performance}

In all a total of 11 WATS were issued to the students. i.e. one per week over the semester. An example frequency plot of students' performance is shown in Figure 3. Apart from 2004-05, the shape of the distributions is similar across the cohorts. All profiles are negatively skewed with the peak occurring between scores of $60-80 \%$. The peak in the highest class also attracts around $25 \%$ of the cohort.

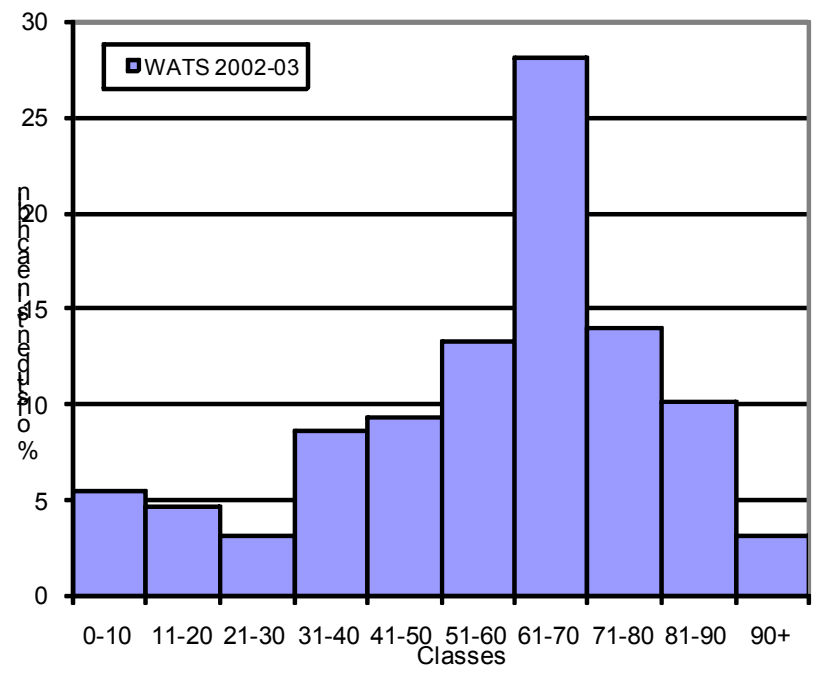

FIGURE 3

RELATIVE FREQUENCY DISTRIBUTIONS OF THE STUDENTS WATS SCORES

A summary of the descriptive WATS statistics for each of the cohorts is given in table IV.

TABLE IV

\begin{tabular}{c|cccc}
\multicolumn{5}{|c}{ COHORT PERFORMANCE ON THE WATS } \\
& $2002-03$ & $2003-04$ & $2004-05$ & $2005-06$ \\
\hline Mean \% & 56.4 & 63.5 & 59.5 & 66.9 \\
P25 & 46.0 & 53.1 & 46.9 & 56.6 \\
P50 & 61.6 & 66.8 & 61.8 & 71.2 \\
P75 & 70.8 & 77.6 & 75.3 & 89.3 \\
SD & 22.4 & 19.4 & 21.1 & 19.6 \\
$>$ 34\%* & $107(84)$ & $123(93)$ & $144(88)$ & $161(94)$ \\
N (exam) & 128 & 133 & 163 & 172
\end{tabular}

The student performance on the WATS, although interesting, is not of primary importance to the research. That is the WATS primarily set out to stimulate engagement and motivate student learning and understanding. Hence the validity of the WATS should be judged on measures of those characteristics and not on the students' performance on the WATS tasks per se. To help judge the validity of the WATS the following section presents the students' examination scores. The use of examination scores to judge student performance is particularly pertinent because it was the poor examination performance in $2000 / 01$ that stimulated this research activity and the subsequent development of the WATS assessment programme.

In addition to presenting post-WATS cohort examination comparisons, comparisons are also made to the pre-WATS cohort (2001/02). The pre-WATS cohort can be viewed as a control group in that they were not exposed to the WATS approach to assessment. During the period of investigation, 2001/02 to 2005/2006 inclusive, the module descriptors and the main teaching practices remained reasonably constant. The significant change was the replacement of the one-off in-module phase test, used during the 2001/02 session, with the WATS approach to assessment.

TABLE V

\begin{tabular}{|c|c|c|c|c|c|}
\hline & \multirow{2}{*}{$\begin{array}{l}\text { EXAMINATION } \\
\begin{array}{c}\text { Without WATS } \\
2001-02 \\
\end{array}\end{array}$} & \multicolumn{4}{|c|}{$\begin{array}{l}\text { CE, PRE- AND POST WAT } \\
\text { With WATS }\end{array}$} \\
\hline & & 2002-03 & 2003-04 & 2004-05 & 2005-06 \\
\hline Mean \% & 39.4 & 47.1 & 42.2 & 51.6 & 33.5 \\
\hline SD & 24.1 & 23.7 & 21.3 & 22.6 & 23.2 \\
\hline$>34 \%{ }^{*}$ & $63(50 \%)$ & $88(69 \%)$ & $83(62 \%)$ & $125(77 \%)$ & 75 (44\%) \\
\hline P10 & 10.4 & 15.1 & 13.0 & 20.0 & 7.0 \\
\hline P20 & 17.0 & 25.0 & 20.4 & 30.0 & 11.2 \\
\hline P25 & 20.0 & 29.0 & 27.0 & 36.5 & 14.0 \\
\hline P30 & 25.0 & 33.1 & 31.6 & 40.0 & 16.3 \\
\hline P40 & 30.6 & 40.0 & 39.8 & 48.0 & 22.4 \\
\hline P50 & 35.0 & 48.0 & 43.0 & 55.0 & 27.5 \\
\hline $\mathrm{P} 60$ & 41.0 & 53.0 & 48.0 & 61.0 & 37.6 \\
\hline P70 & 50.8 & 60.7 & 52.4 & 67.0 & 44.0 \\
\hline P75 & 57.0 & 65.0 & 56.0 & 69.0 & 52.0 \\
\hline P80 & 61.0 & 70.0 & 60.2 & 71.0 & 53.0 \\
\hline P90 & 76.6 & 81.0 & 67.0 & 78.0 & 69.9 \\
\hline$N($ exam) & 125 & 128 & 133 & 163 & 172 \\
\hline
\end{tabular}

* $35 \%$ is considered the typical pass-fail boundary, hence $>34 \%$ is considered a minimum pass.

Exploration of the examination data presented in Table V shows that improvements arose in most of the examination performance indicators. The mean examination score improved from the pre-WATS value of $\sim 39 \%(2001 / 02)$ to $\sim 47 \%(2002 / 03), \sim 42 \%(2003 / 04)$ and $52 \%(2004 / 05)$. The median scores for the years 2002-03, 2003-04 and 2004/05 also improved. Significantly, in the years 2002/03, 2003/04 and 2004-05 the median is above the pass mark. This was not the case for the pre-WATS cohort. Related to the 
Session S2B

increase in the cohort medians, is the increased number of students that scored over $34 \%$ in the exam, the typical pass boundary. By definition this figure also rose, and increased from $63(50 \%) 2001 / 02$ to 88 (69\%) 2002/03, $83(62 \%)$ 2003/04 and $125(77 \%)$ 2004/05 after the WATS were introduced. Additionally, for all years, excluding 2005/06, there is an increase in student performance in the majority of percentiles. The largest gain, that is the difference between the post-WATS percentiles compared to the pre-WATS percentiles, occurs around the middle percentiles, 50th in 2002/03 and 2004/05 and the 40th in 2003/04.

The exact cause of the downturn in performance for $2005 / 06$ is unclear. Observations made by some of the students suggest that some students may have been subverting the system. It appears that some students had access to worked solutions which they were following 'blindly' and without actually engaging in the task. Subverting the system creates two problems; First, the students are not able to really see themselves what they understand and what they don't and second, in subverting the system the teachers do not gain insights into the misconceptions that this cohort has. In subverting the system, the teachers perceive there is little to correct or reinforce in the following teaching sessions.

Rather than focus just on the WATS or examination scores, correlations between these two have also been undertaken, A summary the correlations for all of the cohorts is shown in Figure 4. Individual students are shown as separate entries on the graphs and are denoted by un-filled circles. The solid line represents the relationship WATS score $=$ examination score. Hence any student obtaining a higher score in the WATS than the examination will be positioned below the solid line. Likewise, any student obtaining a higher score in the examination than the WATS will be positioned above the solid line. The dashed line in represents the line of best fit between the WATS and examination scores.

FIGURE 4

EXAMINATION AND WATS SCORE CORRELATIONS - ALL YEARS (N=596)

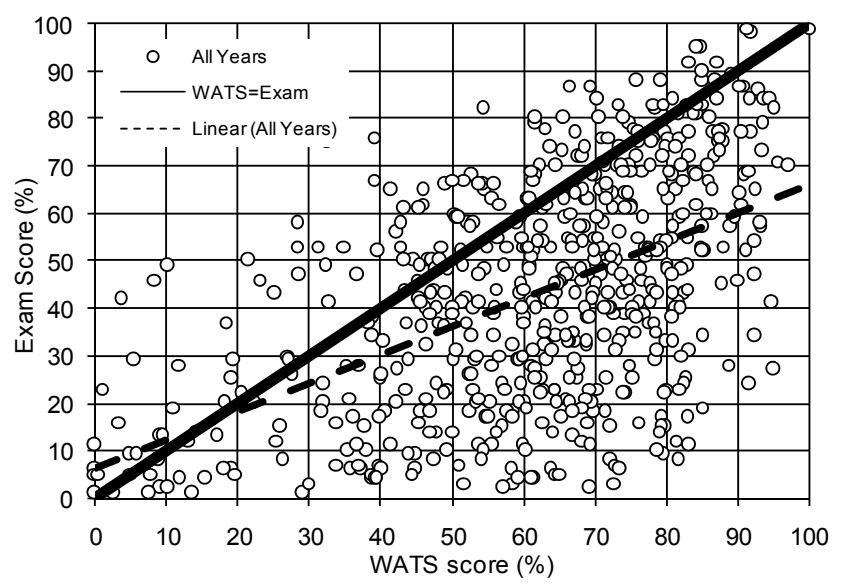

Figure 4 demonstrates that more students scored higher in the WATS than they did in the examination. This relationship exists for all the cohorts exposed to the new assessment programme - see Table VI.

TABLE VI.

NUMBERS OF STUDENTS SCORING HIGHER OR EQUAL TO THEIR WATS

NUMBERS OF STUDENTS SCORING HIGHER OR EQUAL TO THEIR WATS
\begin{tabular}{c|c|c|c|c|c} 
& SCORE IN THE EXAMINATION \\
& $2002-03$ & $2003-04$ & $2004-05$ & $2005-06$ & All years \\
\hline Exam >= WATS & $43(33.6 \%)$ & $17(12.8 \%)$ & $51(31.3 \%)$ & $12(7 \%)$ & $123(20.6 \%)$ \\
\hline $\mathrm{n}($ exams $)$ & 128 & 133 & 163 & 172 & 596
\end{tabular}

Although it is of interest to note the student's comparative performance on the WATS and the examination there is no reason to expect the students to gain an identical score on the separate and different assessment methods. What is more important is an exploration of the hypothesis that a high WATS score implies a good understanding of the subject which will subsequently be accompanied by a high score in the examination. This implies a positive correlation between the students' examination and WATS score. Indeed for all cohorts a positive correlation was observed.

\section{The student view}

Previous sections described the impact of the WATS approach to assessment on the students' study behaviors and their examination scores. This section supplements those results and presents the students' perception of the value of the assessment programme. The student view was collected by a 13 item, closed-question WATS-specific questionnaire. For each of the items the students were presented with a rating scale and asked to respond if they strongly agreed, agreed, neither agreed nor disagreed, disagreed or strongly disagreed with the statements. Fragments of the statements, which were presented as positive items, are included in Table VII.

TABLE VII

Student responses to the WATS specific questionnaire

\begin{tabular}{|c|l|l|l|l|l|}
\hline Rank & Question Fragment & $2003-04$ & $2004-05$ & $2005-06$ & all years \\
\hline 1 & WATS help in exam & $2.24(2)$ & $1.70(1)$ & $1.98(2)$ & $1.97(1)$ \\
\hline 2 & Student unique data is excellent & $2.15(1)$ & $2.03(3)$ & $1.87(1)$ & $2.01(2)$ \\
\hline 3 & League table excellent & $2.31(4)$ & $1.87(2)$ & $2.07(3)$ & $2.07(3)$ \\
\hline 4 & Like getting a mark & $2.26(3)$ & $2.10(5)$ & $2.16(4)$ & $2.17(4)$ \\
\hline 5 & Other subjects could benefit & $2.45(8)$ & $2.06(4)$ & $2.19(5)$ & $2.23(5)$ \\
\hline 6 & Do well if understand... & $2.32(6)$ & $2.19(6)$ & $2.49(9)$ & $2.34(6)$ \\
\hline 7 & No lateness excellent idea & $2.31(5)$ & $2.40(7)$ & $2.40(6)$ & $2.37(7)$ \\
\hline 8 & Overall WATS excellent & $2.41(7)$ & $2.42(8)$ & $2.48(8)$ & $2.44(8)$ \\
\hline 9 & Weekly is excellent & $2.50(9)$ & $2.52(10)$ & $2.41(7)$ & $2.48(9)$ \\
\hline 10 & Still do if did not count & $2.97(12)$ & $2.46(9)$ & $2.87(11)$ & $2.76(10)$ \\
\hline 11 & Trust data collection and marking & $2.62(10)$ & $2.79(11)$ & $2.95(12)$ & $2.79(11)$ \\
\hline 12 & WATS do not hinder other studies & $2.94(11)$ & $2.96(13)$ & $2.85(10)$ & $2.92(12)$ \\
\hline 13 & Really like doing & $3.28(13)$ & $2.95(12)$ & $3.12(13)$ & $3.10(13)$ \\
\hline
\end{tabular}

Valuable insights arise from the students' responses presented in Table VII. First, there exists good agreement between those features of the assessment that are liked as well as those that are disliked by each of the cohorts. This suggests that the feedback is reliable and not biased or skewed by one cohort's experience. Specific points of interests to arise form the feedback includes the students' indication that they think the WATS will help them in the exam (1/13 and they like getting a mark for their efforts (4/13). Further, although ranked at 8/13, the students are still in agreement that overall the WATS are excellent (q13). Given the above it is disappointing to note that many of the 
Session S2B

students indicated they would not do the WATS unless they countered towards the module grade ( $q 7$ 10/13). This point is perhaps supported by the students' response to question, $I$ really like doing the WATS (q9 13/13). In support of one of the themes behind the development, a learning orientation, the students like the use of student unique data (q3 2/13) and also respond positively to the question you only do only do well in the WATS if you understand the subject (q1 6/13). The assessment is trying to stimulate learning, understanding and appropriate study behaviors.

In addition to the closed-questions the students were invited to respond to the question, 'now you have completed the WATS what comments do you have regarding this approach to teaching, learning and assessment'? 309 students responded. A summary of the coding of the responses suggests four themes exist these are:

1.The assessment programme creates a learning orientation. This theme arises from the students' responses that highlight the assessment programme; encourages engagement; supports the lectures and; appropriately distributes their effort across the semester. Example response leading to this theme, 'It gave me a good reason to stop and make time to think and study for the problems given to us via wats. a good way of learning'. (S158, 2005-06)

2. The assessment programme helps to develop self awareness. Linked to the learning oriented theme is the students' awareness that the assessment programme created a self awareness of their learning. That is the assessment programme; helped them learn more and; shown them where their gaps in their knowledge exist. One student writes 'a highly stressful experience! seriously!! but $i$ can say its better than having a heavier weighted exam paper. it felt good to know how you were doing week by week, especially when you were doing well. Being assessed throughout a course instead of all at the end is a much better way to see how well someone is doing. That especially applies to me'. (S54, 2003-05)

3 . There exists a goal-oriented approach to learning. Although the students note the positive consequences of engagement this theme arises due to the responses that; are focused on examination preparation, rather than learning and; raise concerns about the time, effort and the associated grade structure. An example response coded to create this theme includes, 'I'm sorry but $i$ didn't like this approach, mostly because $i$ think it has a very low influence on the final mark compared to the effort in time it requires.' (S40,2003-04).

4. The students perceive the existence of an unfair marking system. This theme arises due to the students; questioning the marking system; being concerned about coupledquestions and; indicating they would prefer noncomputerised marking. Example response from this theme ' $I$ feel that the principle behind the idea (i.e. having an assessed sheet every week, with individual data) is a good idea, however $i$ do not feel comfortable with a computer system marking my results. ifeel it would be far better if the lecturers/tutors should sit down and mark it through themselves. $i$ know this would mean a lot of work for them to do, but if they're prepared to set the work, then they should be prepared to mark it' (S24, 2005-06)

Overarching the above themes is an overwhelming conclusion from the students' responses that, by their own admission, the WATS approach to assessment was valued and of benefit; 268 of the 309 responses were coded as such.

\section{CONCLUSION}

The WATS approach to assessment was developed to respond to a module with high student failure rates. The new assessment programme drew on suggested good practice and set out to establish a more purposive alignment between the teaching, learning and assessment. The results gathered over four years since the use of the assessment programme suggests the students are benefitting from its use.

There are consistently high numbers of students engaging with the weekly tasks and also a visible trace of student thinking and engagement on the tasks in the days preceding their submissions Minor concerns are raised about the timing of some of the student responses. Across the cohorts a consistent $10-15 \%$ of the students submit their work two hours before the midnight submission deadline. The students themselves comment that the WATS approach to assessment has stimulated their engagement with the module in a way that otherwise may not have occurred.

The themes underpinning the development are picked up by the students too when asked to provide their views of the experience. Although many students valued this approach to assessment and thought it would help them in the examination, many also indicated they would not have responded to the tasks if they did not count towards the grade for the module.

\section{REFERENCES}

[1] Biggs, J, Teaching for Quality Learning at University, Society for Research in Higher Education and Open University Press. 2003.

[2] Ramsden, P, Learning to teach in Higher Education, 1991'

[3] Gibbs, G, "Improving Student Learning Through Assessment", Journal of Geography in Higher Education, 27:2, 123-132

[4] Boud, D "Assessment and Learning: Contradictory or Complementary?" in P. Knight (ed.) Assessment for Learning in Higher Education 1995, pp.35-38

[5] Brown, G, Assessing Student Learning in Higher Education. 1997

[6] Chickering, A, W, and Gamson, Z, F "Seven principles for good practice in undergraduate education" American Association of Higher Education Bulletin 1987, pp.3-7

[7] Bransford, J. D., Brown, A. L., and Cocking, R. R. (eds.), 1999, How People Learn: Brain, Mind, Experience, and School, 1999

[8] Gibbs, G \& Simpson, C. (in press) Does your assessment to support your students' learning? Journal of Teaching and Learning in Higher Education.

[9] Nicol, D, J. and Macfarlane-Dick, "Formative assessment and selfregulated learning: A model and seven principles of good feedback practice.", Studies in Higher Education, 31, 2, 2006, 199-216.

[10] Hornby, W, "Dogs, Stars, Rolls Royces and Old Double Decker Buses: Efficiency And Effectiveness In Assessment", Reflections on Assessment: Volume 1, Quality Assurance Agency for Higher Education, 2005

[11] Russell, M, B, Intelligence-led teaching: Using the students' conceptions to drive the learning-conversation. Proceedings of the International Conference of Engineering Education, 2006 